\title{
Managing the Northern Australian Coastline through Indigenous Protected Areas
}

\author{
Dr Nanni Concu and Ms Katherine May \\ Centre for Aboriginal Economic Policy Research, Australian National University, Canberra, Australia
}

Paper presented at the $10^{\text {th }}$ Littoral Conference: Adapting to Global Change at the Coast 21 - 23 September 2010, London, UK properly cited. 


\begin{abstract}
Indigenous-owned land currently makes up more than 40 per cent of Australia's Northern Territory, including 87 per cent of the coastline (Sithole, Whitehead and Kerins 2007). It contains some of the most biodiversity rich lands in the country (Altman, Buchanan and Larson 2007). In Northern Australia, climate change is predicted to impact on water availability and species composition, abundance and diversity, with likely loss of native flora and fauna (Dunlop and Brown 2008), as well as increase the likelihood of extreme weather events (Green, Jackson and Morrison 2009). Research also shows that this region faces major threats from feral animals, exotic weeds, changed fire regimes and marine and terrestrial pollution (Altman and Whitehead 2003).
\end{abstract}

Indigenous Protected Areas (IPAs) are part of Australia's National Reserve System (NRS). They provide a management framework for Indigenous-owned land in which Traditional Owners voluntarily conserve biodiversity and protect their culture.

In this paper we critically analyse the effectiveness of the IPA program as a model of good practice for managing Indigenous-owned coastal zones in northern Australia.

The paper focuses on two IPAs located in the Arnhem Land Coast bioregions in the Northern Territory. Data on management effectiveness was collected through a series of questionnaires to land managers, field work and participant observation in the study areas.

The analysis indicates that the IPAs under study suffer from a problem of scale-mismatch. Some ecological processes and environmental threats are not confined to the IPA boundaries. Hence, management activities within an IPA can only mitigate environmental problems that originate outside IPA boundaries. A lack of integrated coastal zone management also limits the ability to manage environmental risks within IPAs. Further, overlapping governance arrangements, institutions and processes affect IPA management effectiveness. While Australia's IPA program is being hailed as an effective environmental management framework for biodiversity conservation, our analysis indicates that there is a scale mismatch in terms of both ecological processes and institutional spatial arrangements. 


\section{Introduction}

Australia's Indigenous Protected Areas (IPAs) are terrestrial units for environmental and cultural conservation on Indigenous-owned land. Traditional owners voluntarily declare their terrestrial estate an IPA, and manage it according to International Union for the Conservation of Nature (IUCN) guidelines. The Australian Federal government formally recognises and endorse IPAs as part of Australia's National Reserve System, and provides financial resources through several funding schemes. However, IPAs have no legal basis, that is they are not regulated by any Commonwealth, State or Territory legislation. In times of dwindling government support for Indigenous Australians living remotely, IPAs are emerging as an instrument to promote economic development through natural resource management.

IPAs are assemblages of cultural, historical, institutional, and ecological structures and processes interacting in a geographical space. They are the product of relations between actors with different powers, capacities, opportunities, constraints, access to, and rights over, resources (Brenner 2001). They are fluid and contested. Our analysis of the conservation effectiveness of IPAs offers a way of revealing some of the complex and interlacing social, institutional and ecological scales within which IPA management is embedded. In turn, this information is especially important to address and adapt to changing environmental conditions.

For the purpose of this study data was collected through a questionnaire to the managers of the selected case studies. The questionnaire design is based on the World Commission for Protected Areas (WCPA) Framework which provides an overarching framework to assess the management effectiveness of protected areas throughout the world (Hockings et al. 2006). Information on the case study areas is also drawn from the authors' field work and participant observation in the study areas.

This paper is structured in four parts. We examine the institutional scales of IPA (section 1). In section 2 we introduce the study areas, and present the data obtained through questionnaires and field work. We discuss the data in section 3 . Section 4 contains the conclusions. 


\section{Scale configuration of IPAs.}

Australian IPAs are institutional arrangements for environmental and cultural conservation. They are a space where both environmental and political processes shape planning, management and governance of the human/environment interaction. In Figure 1 we illustrate the connections between the institutional and environmental scales. A variety of sociopolitical processes and institutions at the global, national and local level contribute to the spatial construction of IPAs.

At the international level, for instance, the International Union of the Conservation of Nature (IUCN) sets the global framework for IPAs (Dudley 2008). These guidelines revolve around several principles including the protection of Indigenous land and sea, and the people and cultures they contains, from external threats; the recognition of Indigenous resource rights, institutions, and knowledge for the sustainable use of natural resources; and support Indigenous development priorities (Beltrán 2000).

In the early 1990's, Australia sough to establish a comprehensive, adequate and representative system of protected areas (NRMMC, 2005), in order to expand the National Reserve System (NRS) and address the lack of representation of certain bioregions in line with its obligations to the International Convention on Biological Diversity. It soon became apparent that Indigenous people owned large areas of land, including whole bioregions that were underrepresented in the NRS (Szabo \& Smith 2003).

Indigenous-owned land currently makes up more than 40 per cent of the Northern Territory, including 87 per cent of the Territory's coastline (Sithole et al. 2007). This has come about as a result of the Aboriginal Land Rights Act (ALRA) 1976 which provides the strongest form of Indigenous land rights in Australia. The scale of Indigenous land and sea management is usually tied to clan estates and language areas in which Indigenous groups have inherited responsibilities to use and manage certain discrete areas of country (Smyth et al. 2004). 


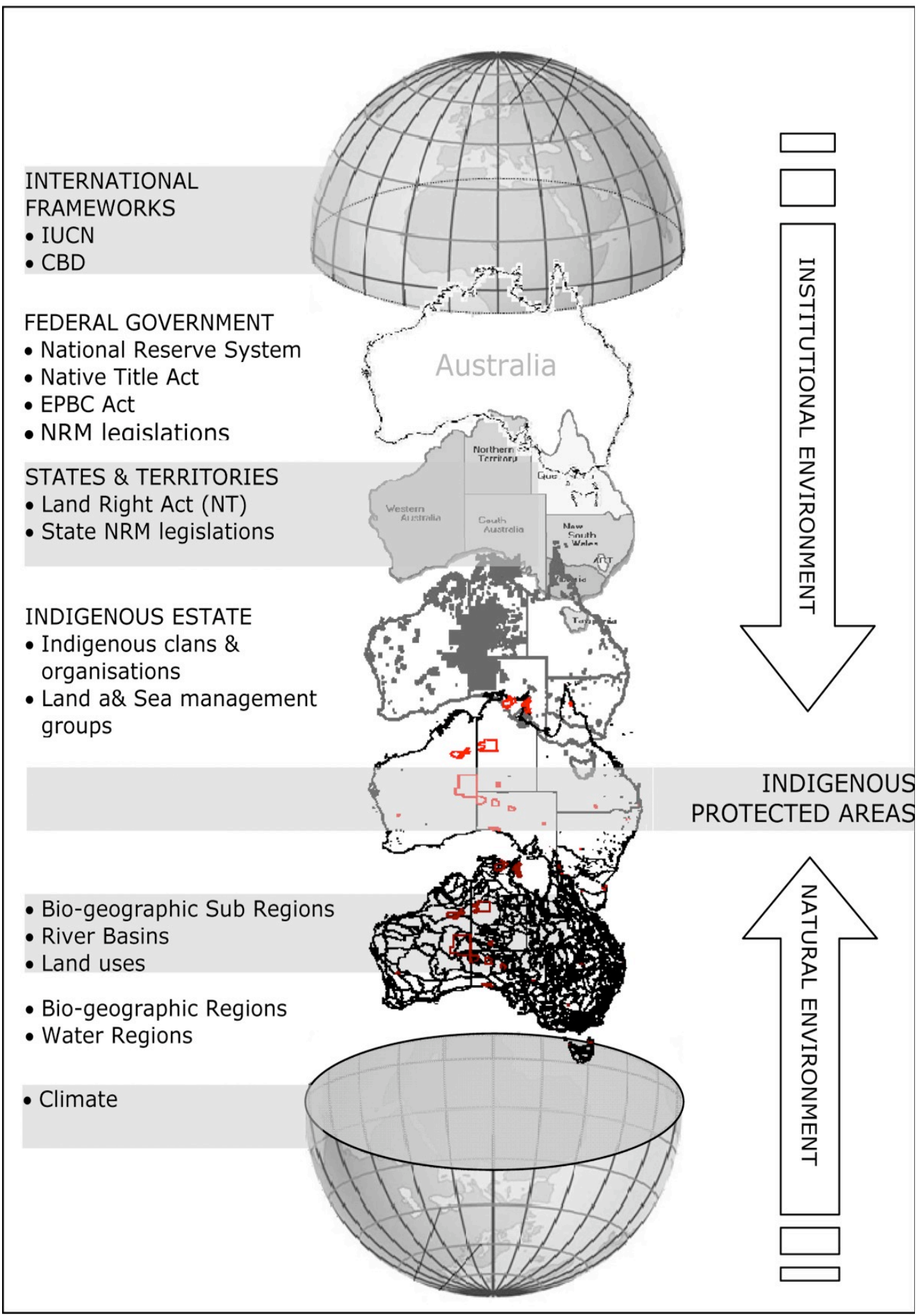

Figure 1. Institutional and ecological scale of Australia's IPAs.

Numerous formalised community-based Indigenous natural resource management institutions have emerged, particularly in northern Australia. They are carrying out a suit of 
land management activities on the Indigenous estate, using traditional land use practices alongside modern conservation methods to tackle new and emerging threats. These include fire management, feral animal and weed control, biodiversity monitoring and threatened species protection and cultural heritage activities (Putnis et al. 2007). Evidence suggests that their work is contributing to a broad range of environmental, cultural, social, education, health, employment and economic development outcomes (see Burgess \& Johnson 2007; Garnett \& Sithole 2007; Luckert et al. 2007).

Since the late 1990's, Indigenous NRM has been supported through the IPA program. There are now 38 declared IPAs across Australia covering over 23 million hectares, with consultation projects under way for other 40 (DEWHA, 2010a). IPAs currently represent some 23 per cent of the NRS and they include some of the most biodiverse and highly valued of all NRS properties (Gilligan 2006). The government provides planning and management assistance through its IPA program ${ }^{1}$, which is administered by the Department of Environment, Water, Heritage and the Arts (DEWHA) under the Australian Government's overarching national framework for environmental management Caring for our Country (Australian Government 2010). Funding is provided on an annual basis. The IPA program is complemented by DEWHA's Working on Country (WOC) program which provides funding for wages (May 2010). Therefore the security and viability of IPAs is reliant on financial support from government as many Indigenous land-owners lack the resources to manage their vast estates independently (Langton et al. 2005).

Recent research indicates that climate changes is likely to affect coastal communities in Northern Australia through (Green, Jackson and Morrison 2009:1):

- Increasing atmospheric carbon dioxide levels that will alter plant growth

- Increasing temperatures that will affect human and natural systems

- Rising sea levels that pose threats to coastal settlements and ecosystems

- Ocean acidification that will endanger coral reefs and affect marine food chains

- Seasonal change in rainfall with likely increases in intensity in the rainy season for some regions which will affect access and water supplies

\footnotetext{
${ }^{1}$ The IPA program budget totals $\$ 50$ million over five years (2008-09 to 2012-13), to support existing IPAs and develop new ones through consultation projects (DEWHA 2010b).
} 
- Greater cyclone intensity that will increase inundation of coastal areas.

Preliminary analysis of the significance of IPAs for biodiversity conservation shows that at the national level IPA are not contributing significantly to the protection of environmentally significant bioregions and river catchments ${ }^{2}$. The main factor explaining the establishment of IPAs is the security of Indigenous land tenure. Other land uses such as pastoralism limit the scale and extent of IPAs and hence the role they can play in conservation. Further, the condition of the environment, measured by a set of environmental indicators, does not appear to be a relevant factor in determining the establishment and size of IPAs (Concu \& May 2010).

\section{Two case studies}

\subsection{Dhimurru IPA}

Dhimurru (formerly known as Dhimurru Land Management Aboriginal Corporation) was established in 1992, as Yolngu (Indigenous people from East Arnhem Land) grew more and more concerned about the impact of an increasing non-Indigenous population that followed the establishment of a bauxite mine and processing plant. Traditional owners run and control the organisation through the Dhimurru Board

(Wa:nga-Watangu Yolngu) that includes representatives of 17 clans with interests in the region and sets management and access to recreational areas requirements (Dhimurru 2008). Indigenous staff include a Yolngu managing director, a senior cultural advisor, Yawarrin (men) Rangers (divided in IPA Rangers and Sea Country Rangers), Miyalk (women) Rangers, and a permit officer. Non-indigenous staff include an executive officer, three project facilitators, and administrative staff.

In 2000 Yolngu declared the Dhimurru IPA, covering around 92,000ha of land and 9,000ha of adjacent marine areas in the Gove Peninsula (Figure 2).

\footnotetext{
${ }^{2}$ Biogeographic regions and river catchments are basic units for environmental management and protection according to the Interim Biogeographic Regionalisation for Australia 2001. Australia's NRS uses the IBRA to identify national conservation priorities (DEWHA 2004).
} 
The IPA contains areas of important cultural and environmental values, hosting a significant representation of Australia's Arnhem Coast sub-bioregion ARC-3 (DEWHA 2004). Environmental values include high plant diversity, intact faunal assemblages, significant DhimumuIPA
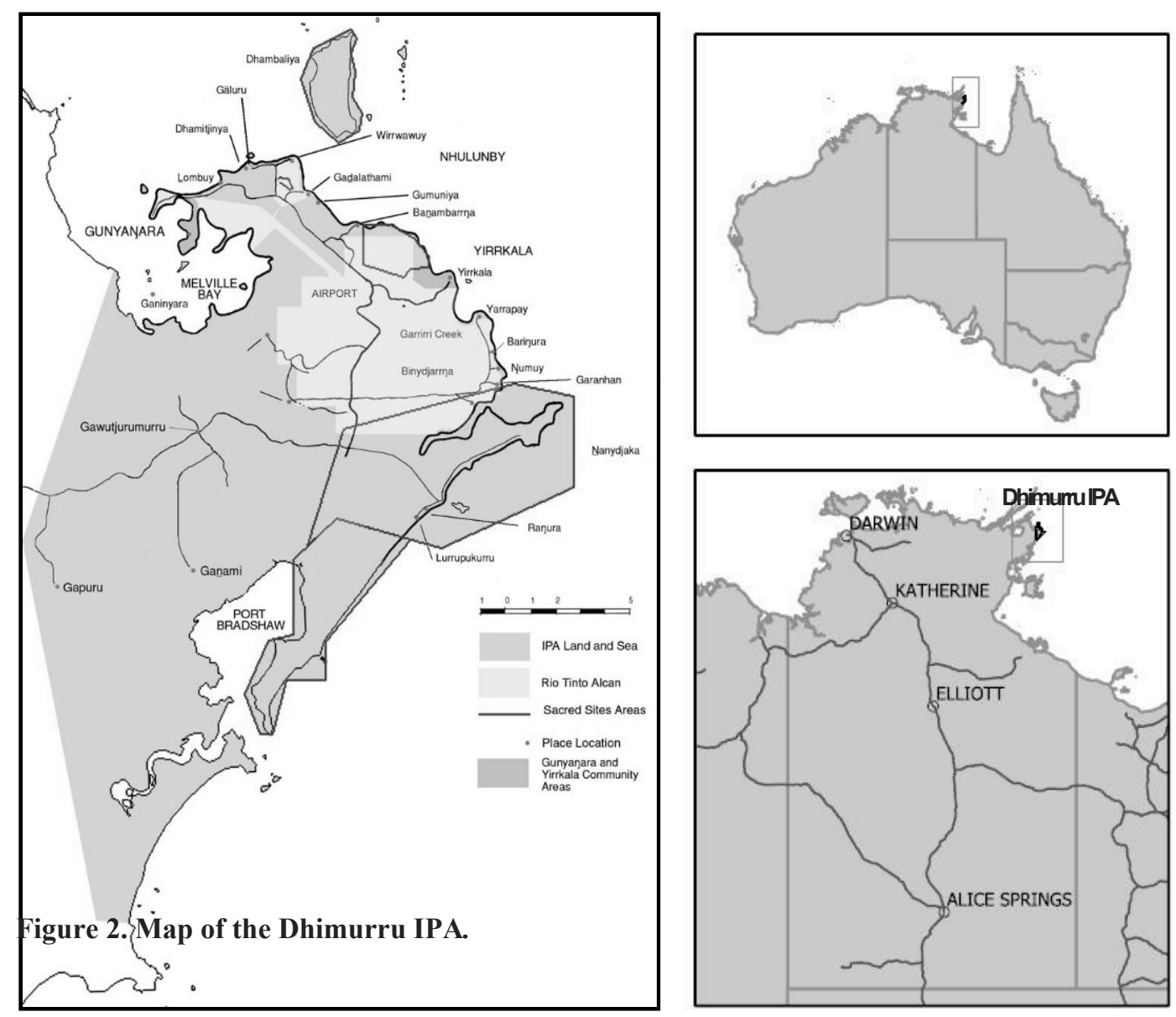

feeding and nesting sites for threatened species of marine turtles and sea birds (Dhimurru 2008). Dhimurru IPA surrounds land leased to Rio Tinto Alcan for bauxite mining and processing, and the townships of Nhulunbuy, Yirrkala and Gunyangara.

Primary focus of Dhimurru's activities is the protection of Yolngu values and conservation and enhancement of IPA natural and cultural values (Dhimurru 2006, 2008). Dhimurru also fosters 'both-ways' management by integrating Yolngu and non-Indigenous sciences. The IPA is managed according to IUCN Category $V$ guidelines, for conservation and recreation. Dhimurru's activities have interconnected goals: people management, environmental monitoring, conservation and restoration, heritage and cultural activities. 
People management aims at limiting and monitoring use, compliance, and access. Limits on use and access prevent conflict with local Indigenous communities, protect sites of cultural and environmental significance by avoiding damage caused by vehicle movements (e.g. weed and alien ant spreading) as well as by inappropriate behaviour (e.g. vandalism). Dhimurru Rangers also carry out environmental management and conservation. This includes: crocodile trapping, tagging and relocating; weeds monitoring, treatment and eradication, discarded ('ghost') net recovery and turtle rescue, Australian Quarantine and Inspection Service (AQIS) contracted work (mosquito, ant and weed sampling and monitoring), marine debris and beach clean-ups (often with the support of volunteers).

One of the main threats to the Dhimurru IPA relates to the residential and commercial development within the IPA that is, the bauxite mine and refinery, infrastructure, and the housing and settlement in the townships of Nhulunbuy, Yirrkala and Gunyangara. Local transport networks and particularly the Central Arnhem Highway that intersects the IPA provide a potential threat mainly in terms of the spread of weeds. Related to its proximity to relatively large non-Indigenous settlements, recreational activities and tourism may also threaten the integrity of the IPA. Commercial logging and wood harvesting of the savannah woodland is also a threat. Fire remains a significant threat due to natural system modifications, despite the annual controlled burning activities of the Dhimurru managers and other land owners. Significant ecological threats include invasive plant species and feral animals as well as severe weather events such as cyclones that may be linked to long-term climatic change.

Dhimurru is the only IPA whose boundary includes coastal waters. This has come about as a result of Indigenous land-owners' demand for the inclusion of islands within the IPA. However, the managers of Dhimurru IPA have expressed concern about the effectiveness of the scale of the IPA to address larger scale ecological processes, such as those listed above (weeds, feral animals and mining). This is partly related to the fact that there are no appropriate regulations in place to effectively control land and sea use and activities within the IPA. Indeed, declaring an IPA does not extend the managers' capacity and enforcement powers, beyond those recognised through existing land rights legislation. 
Dhimurru's current budget is mostly reliant on funding from the IPA and WoC programs. This is sufficient for carrying out regular operations, but does not provide resources for adapting and addressing emerging environmental problems, possibly related to climate change. The overall budget for the financial year 2009/2010 was around Aus $\$ 2$ million.

\subsection{Djelk IPA}

Djelk Rangers were established under the auspices of Bawinanga Aboriginal Corporation in 1991. The Djelk IPA was declared in 2009. It extends over 673,200 ha stretching from the Central Arnhem Plateau to the Arafura Sea in the Arnhem Coast sub-bioregion ARC-2 (Figure 3). The Djelk IPA comprises a biodiversity-rich landscape, home to iconic species such as saltwater crocodiles, and the richest variety of reptiles in the world (DEWHA 2010c). Senior TOs guide and control the management of the IPA through an Advisory Committee consisting of representatives of 107 landowning clans. 

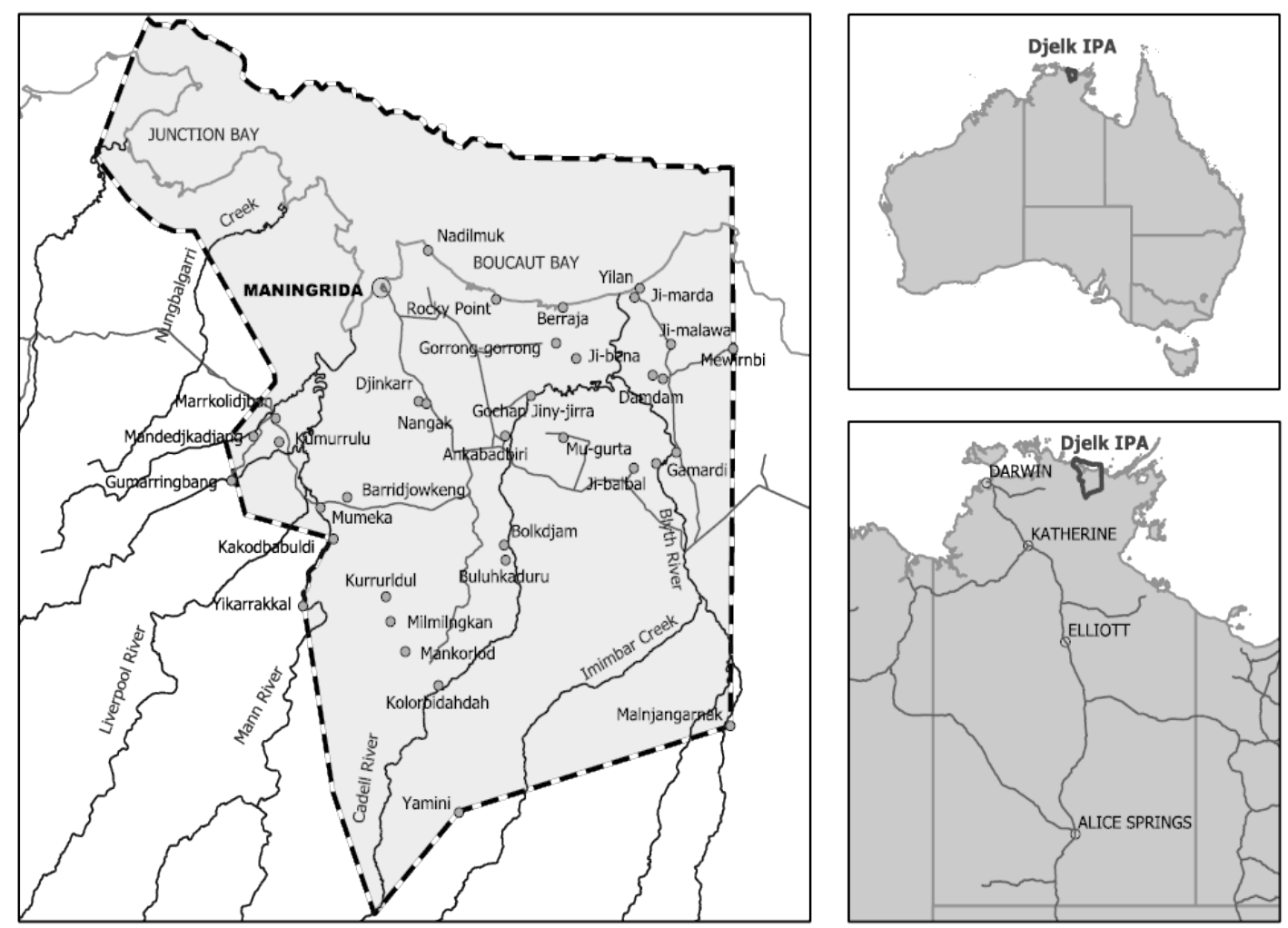

Figure 3. Map of the Djelk

Djelk currently employs 35 Indigenous Rangers, a non-Indigenous Ranger coordinator and a Special Project Officer. Rangers are divided in three groups (Sea, Land, and Women Rangers). For the financial year 2008/2009, Djelk Rangers had a budget of around $\$ 1.7$ million, $85 \%$ of which comes mostly from the IPA and WOC programs, and $15 \%$ is revenues from fee-for service contracts.

Major responsibilities of Land and Women Rangers include fire management and selective burning, feral animal control, and weed treatment. These activities aim at maintaining the biodiversity and the productivity of the land through the use and transfer of both Indigenous and non-Indigenous knowledge (BAC 2009). Under fee-for-service agreements with Australian Customs and the Northern Territory Department of Resources-Fisheries, Djelk Sea Rangers patrol over $200 \mathrm{~km}$ of coast to detect illegal foreign and Australian fishing vessels and illegal migration, and to monitor recreational fishing. 
The main threats to the Djelk IPA are feral animals and invasive non-native species. The two main alien species threatening native biodiversity are mission grass and buffaloes, both introduced for commercial and agricultural purposes in surrounding pastoral properties (Parsons and Cuthbertson, 1992; Smith, 1995). Feral animal are also causing localised erosion and damage to wetlands and sacred sites (Djelk, pers. comm.).

Similar to Dhimurru, Djelk IPA managers consider the scale of the IPA inappropriate to address environmental problems. The area they currently manage extends well beyond the boundaries of the IPA (BAC forthcoming). Unlike Dhimurru, Djelk IPA does not include the $2000 \mathrm{sq} \mathrm{km}$ of sea country they regularly patrol and monitor, notwithstanding the request put forward by the Indigenous land owners.

\section{Discussion}

The case studies show that the extent of Indigenous land owners' powers is limiting their ability to effectively manage their land and sea for biodiversity conservation. External ecological processes, such as the invasion of feral animals and weeds, pose a serious threat to the environmental integrity of IPAs, as do the impacts of surrounding mining and residential areas. Indigenous land and sea managers spend a great deal of their resources to mitigate these threats with limited or no power to to tackle them at the source. They are bearing the costs, with minimal funding and resources, to maintain the environmental integrity of their land to fulfil their cultural responsibilities and obligations to the IPA program. This raises questions about the long-term viability of IPAs for environmental conservation. Government funding for IPAs to mitigate external threats will not be infinitely provided, but the external threats will continue to have an impact if they are not controlled at the source, and are likely to further increase as a consequence of climate change.

Indigenous land-owners' control of land and sea within the IPA boundary also have its limitations. IPAs do not have legal protected area status under Australian statutory law. As such they are apportioned the same statutory laws provided to all Indigenous-owned land, under the ALRA, whether or not it is declared an IPA. Dhimurru has a permit system in place to limit and monitor use, compliance, and access within the IPAs, but its ability to enforce these regulations is limited by a lack of empowering legislation. The IPA program does not provide for increased enforcement powers. 
The case studies illustrate that the decision by traditional owners to declare an IPA can be driven by diverse factors. Their inherent desire to care for their country is very often compounded by external forces and power imbalances; IPAs are a negotiated space between the rights and interests of Indigenous land owners and external agents. For example, it was the external threat posed by the mining lease that Dhimurru decided to declare an IPA. The voluntariness of IPAs has offered Indigenous land-owners some control and agency over the management of their land which is a welcomed step forward from previous provisions. Yet, there is a limit to the extent of their control in the face of competing interests of more powerful actors, and their comparatively limited opportunities and capacity.

The jurisdictional demarcation between land and sea poses a management challenge for Djelk managers. Djelk is demanding recognition of custodial rights beyond the terrestrial boundaries of their IPA. This demand has been recently supported by the 2008 Australia's High Court ruling on the Blue Mud Bay case. The ruling has extended Indigenous rights to exclude activities within the intertidal zones (Morphy and Morphy, 2009). But little progress has been made. Sea Country IPAs continue to be proposed, but the Federal Government has been forthright in clarifying that they are only a "collaborative conservation framework" with no impact on the activities of any non-Indigenous group.

The limited powers and resources of IPA managers affects their ability to effectively adapt to and address new and emerging threats to coastal regions, particularly those related to climate change.

\section{Conclusion}

Australia's IPAs are terrestrial units for environmental and cultural conservation on Indigenous-owned land. But their location and scale don't seem to be related to addressing the national conservation priorities in the Australian landscape. Institutional and economic factors play a more significant role.

The two case studies presented in this paper show that the IPA program does not extend powers of Indigenous land-owners beyond those granted by pre-existing land rights legislation; it simply provides financial support for ongoing management. Their inability to 
address the causes of external threats, or challenge pre-existing development projects within their own boundaries limits their ability to effectively manage their land for the purpose of environmental conservation. It is then questionable ow this institutional arrange can respond to the increasing threats posed by changing environmental conditions related to global warming.

Nevertheless IPA are a step forward in the recognition of Indigenous right and interests in protected area management. They have increased the visibility of Indigenous land-owners and managers, and their role in conserving Australia's biodiversity, hopefully fostering respect for Indigenous peoples and cultures in Australia and beyond.

\section{References}

Altman, J. C., Buchanan G. J., and Larsen, L. (2007) The environmental significance of the Indigenous estate: Natural resource management as economic development in remote Australia. CAEPR Discussion Paper 286/2007, Canberra, CAEPR, ANU.

Altman, J.C., Whitehead, P.J. (2003). Caring for country and sustainable Indigenous development: Opportunities, constraints and innovation, CAEPR Working Paper 20/2003, Canberra, CAEPR, ANU.

Australian Government (2010), Caring for out Country, available at http://www.nrm.gov.au/, last retrieved 05 February 2010.

BAC (2009) Djelk Indigenous Protected Area Management Plan, Bawinanga Aboriginal Corporation, Maningrida.

BAC (2010) Djelk Rangers Annual Report, forthcoming.

Beltrán, J. (2000). Indigenous and Traditional Peoples and Protected Areas: Principles, Guidelines and Case Studies, IUCN, Gland, Switzerland. 
Brenner, N. (2001). 'The limits to scale?' Methodological reflections on scalar structuration, Progress in Human Geography, 25: 4, 591-614

Burgess, C.P. \& Johnston, F.H. (2007) Healthy Country: Healthy People: Indigenous Natural and Cultural Resource Management and Health, Darwin, Menzies School of Health Research.

Concu N., May K., (2010) Institutional and ecological scales of Indigenous Protected Areas in Australia:

A critical analysis

, Paper presented at the International Society for Ecological Economics (ISEE)

11th Biennial Conference: Advancing Sustainability In A Time Of Crisis

22 - 25 August 2010, Oldenburg and Bremen, Germany

DEWHA (2004) Interim Biogeographic Regionalisation for Australia (IBRA), Department of Environment, Water, Heritage and the Arts, Australian Government, Canberra.

DEWHA (2010a), Indigenous Protected Areas, Department of Environment, Water, Heritage and the Arts, Australian Government, Canberra, accessed 12 April 2010, available at: http://www.environment.gov.au/indigenous/ipa/index.html

DEWHA (2010b), Indigenous Protected Areas- project assessments, Department of Environment, Water, Heritage and the Arts, Australian Government, Canberra, accessed 12 April 2010, available at: http://www.environment.gov.au/indigenous/ipa/assessment.html

DEWHA (2010c) Djelk Indigenous Protected Area, Canberra, accessed 6 June 2010, available at, http://www.environment.gov.au/indigenous/ipa/declared/djelk.html

Dhimurru, 2006. Sea Country Plan. Dhimurru Aboriginal Corporation, Nhulunbuy.

Dhimurru (2008) IPA Plan of Management 2008-15, Dhimurru Aboriginal Corporation, Nhulunbuy. 
Dudley, N. (ed.) (2008) Guidelines for Applying Protected Area Management Categories, IUCN, Gland, Switzerland.

Dunlop, M., Brown, P.R. (2008), Implications of Climate Change for Australia's National Reserve System: A preliminary assessment, report to the Department of Climate Change, Canberra.

Garnett, S. \& Sithole, B. (2007) Sustainable Northern Landscapes and the Nexus with Indigenous Health: Healthy Country, Healthy People Darwin, Charles Darwin University, and Canberra, Land \& Water Australia.

Gilligan, B. (2006). The Indigenous Protected Area Program: Evaluation. Department of Environment and Heritage, Canberra.

Green D., Jackson S., Morrison J. (2009) Risks from Climate Change to Indigenous Communities in the Tropical North of Australia. Department of Climate Change and Energy Efficiency, Canberra.

Hockings, M., Stolton, S., Leverington, F., Dudley, N., and Courrau, J. (2006). Assessing Effectiveness - A framework for assessing management effectiveness for protected areas, $2^{\text {nd }}$ Ed. IUCN, Switzerland.

Langton, M., Rhea, Z. M. \& Palmer, L. (2005) 'Community-Orientated Protected Areas for Indigenous People and Local Communities', Journal of Political Ecology, 12, 23-29.

Luckert, M. K., Campbell, B. M., Gorman, J T. \& Garnett, S. T. (2007) Investing in Indigenous Natural Resource Management, Darwin, Charles Darwin University Press.

May, K., 2010. Working on country: a Caring for our Country program. CAEPR Working Paper 65/2010. Centre for Aboriginal Economic Policy Research, Canberra. Available on line at: http://www.anu.edu.au/caepr/Publications/WP/2010WP65.php . Last accessed: 06 June 2010. 
Morphy, F and Morphy, H (2008) The Blue Mud Bay case: refractions through saltwater country, Dialogue 28: 15-25

NRMMC (2005), Directions for the National Reserve System: A partnership approach, Natural Resource Management Ministerial Council, Department of the Environment and Heritage, Canberra.

Parsons, W., Cuthbertson, E., 1992. Noxious Weeds of Australia. Inkata Press, Melbourne. Putnis, A., Josif, P. \& Woodward, E. (2007) Healthy Country, Healthy People: Supporting Indigenous Engagement in the Sustainable Management of Northern Territory Land and Seas: A Strategic Framework, CSIRO, Darwin.

Sithole, B., Whitehead, P., \& Kerins, S. (2007) 'Issues in Indigenous Natural Resource Management'. In Luckert, M.K., Campbell, B.M., Gorman, J.T. \& Garnett, S.T. [eds] Investing in Indigenous Natural Resource Management, CDU Press, Darwin, pp. 4-7.

Sithole, B., \& Hunter-Xenie, H., with L. Williams, J. Saegenschnitter, D. Yibarbuk, M. Ryan, O. Campion, B. Yunupingu, M. Liddy, E. Watts, C. Daniels, G. Daniels, P. Christophersen, V. Cubillo, E. Phillips, W. Marika, D. Jackson \& W. Barbour (2008) Aboriginal land and sea management in the Top End: a community-driven evaluation, CSIRO Sustainable Ecosystems, Darwin.

Smith, N., 1995. Weeds of Natural Ecosystems: a Field Guide to environmental Weeds of the Northern Territory. Environment Centre Northern Territory, Darwin.

Smyth, D., Szabo S. and George, M. 2004. Case Studies in Indigenous Engagement with Natural Resource Management, Department of Environment and Heritage, Canberra.

Szabo, S and Smyth, D (2003) Indigenous Protected Areas in Australia, in H, Jaireth and D, Smyth (eds) Innovative Governance: Indigenous people, Local Communities and Protected Areas, Abe Books, New Delhi. 